\title{
COLLECTIE 229 \\ EEN COLLECTIE FILIGRAIN VAN ZILVER EN GOUD \\ IN HET TROPENMUSEUM
}

In 1924 verwierf het Tropenmuseum collectie 229. Het zijn 118 voorwerpen, waarvan 62 van zilver- of goudfiligrain. Het was een legaat, afkomstig van mevrouw O.E.A.E. Wüste - Baronesse von Gotsch die in dat jaar op 75-jarige leeftijd overleed. Kort na haar overlijden werd de door haar en haar man verzamelde collectie voorwerpen van zilver- en goudfiligrain uit 'Azië en Europa' door haar erfgenaam, juffrouw J.G. Fontein te Santpoort, aan het Koloniaal Instituut, Afdeling Volkenkunde, overgedragen. ${ }^{1}$ In de brief over deze schenking staat slechts vermeld: ' 1 partij zilverfiligrain-werk ter waarde van f. 2000; 1 partij goudfiligrain-werk ter waarde van f. 1000.' In een brief van 11 oktober schrijft J.C. van Eerde, directeur van de Afdeling Volkenkunde, aan de Raad van Beheer van het Koninklijk Koloniaal Instituut over deze schenking: 'Door Mejuffrouw J.G. Fontein te Santpoort Huize Spaarnberg is aan onze verzamelingen uit de haar toegevallen inboedel van wijlen Mevrouw Wüste-von Gotsch toegevoegd eene zeer kostbare verzameling filigrainwerk uit Nederlandsch-Indië en andere streken van de wereld.' $2 \mathrm{De}$ collectie is, op een enkel object na, nooit gedocumenteerd. De 'provenance' van de 118 objecten is slechts door herleiding vast te stellen.

\section{De schenkster}

In de zoektocht naar de herkomst van de naam Wüste-von Gotsch dook de naam Adriaan van der Hoop op. Van der Hoop was een $19^{e}$-eeuwse Amsterdamse bankier, die twee belangrijke collecties bijeenbracht: een schilderijenverzameling, die hij aan het Rijksmuseum schonk, en een verzameling belangrijke botanische boeken, die in 1924 terecht kwam in de Universiteitsbibliotheek in Amsterdam. Informatie over Wüste-von Gotsch en het verband met Adriaan van der Hoop bleek te vinden in de recente tentoonstellingscatalogus over de collectie Van der Hoop. ${ }^{3} \mathrm{Na}$ het overlijden van zijn eerste echtgenote trouwde Van der Hoop in 1834 met de weduwe Dieuwke Fontein. ${ }^{4}$ Dieuwke Fontein had uit haar eerste huwelijk een dochter, Suzanne Christina Hofstede, die in 1848 overleed. Suzanne Hofstede was getrouwd met Johann August Andreas Gottfried von Gotsch (1808-1857). Hun dochter, Olga Emma Alexandra Eleonora von Gotsch, Dieuwkes kleindochter, trouwde in 1868 met Justus Rudolf Wüste (18451916). ${ }^{5} \mathrm{Na}$ de dood van haar echtgenoot bleef Dieuwke van der HoopFontein op Spaarnberg wonen. Bij haar dood liet ze het landgoed na aan haar kleindochter Olga Wüste-von Gotsch. ${ }^{6}$ Deze bleef hier wonen tot haar overlijden in $1924 .^{7}$

Justus Rudolf Wüste was een belangrijk man in de Amsterdamse koopmansen financiële wereld. ${ }^{8} \mathrm{Hij}$ werkte als firmant in de door zijn vader opgezette

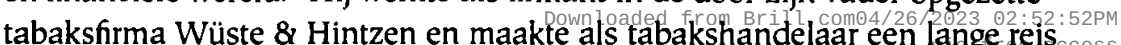




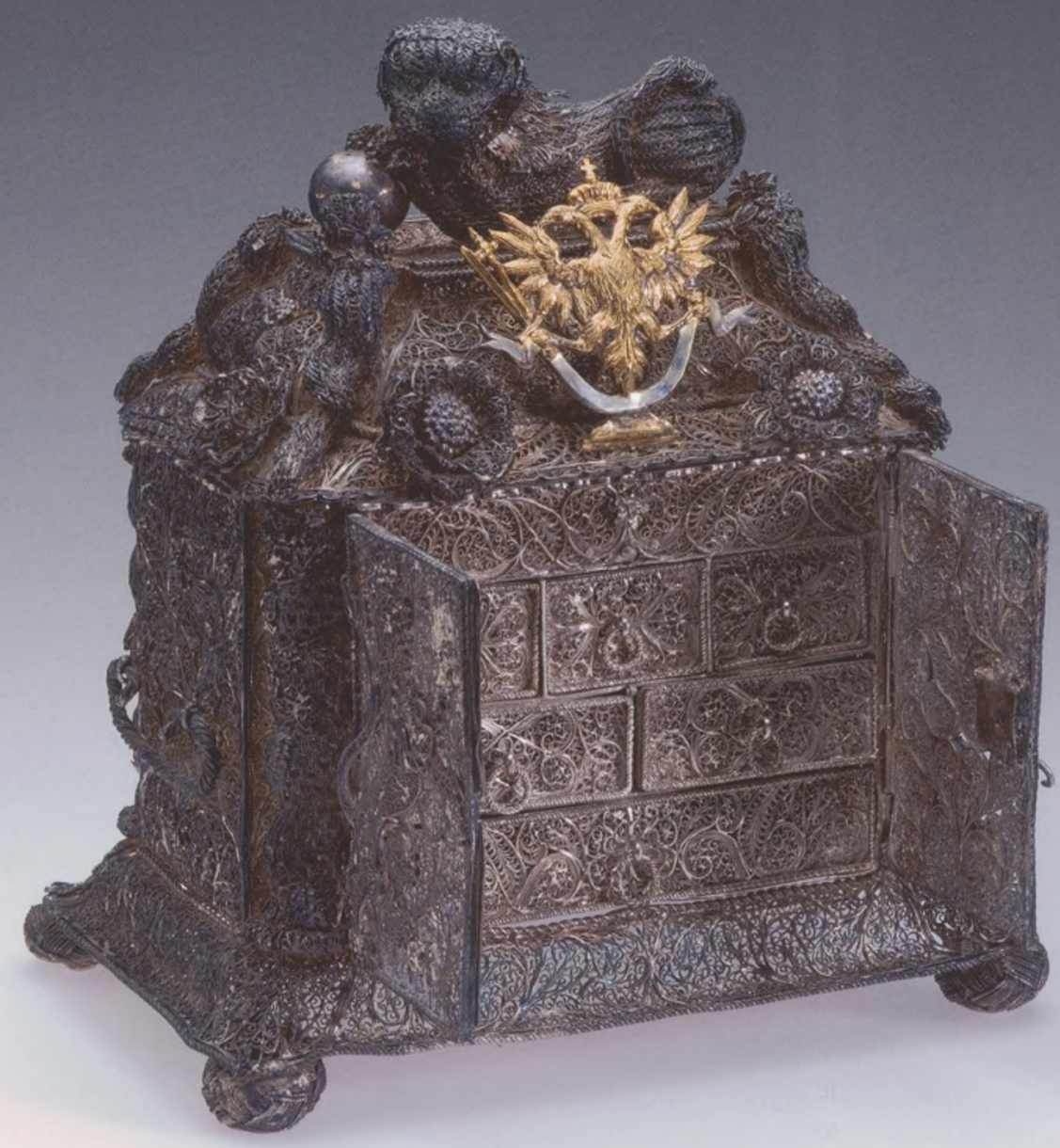

\section{Afbeelding 1}

Bijouteriekistje,

zilverfiligrain en verguld zilver, $15 \times 22 \times 10 \mathrm{~cm}$.,

Chinees werk, $19^{e}$ eeuw,

collectie

Tropenmuseum, nr. 229-117. Foto Paul

Romijn door Indië. Wüste was raadslid in Amsterdam en diende het algemeen belang verder door het bekleden van bestuursfuncties in onder andere de Vereniging Rembrandt, Artis en de Nederlandsche Koloniale Vereniging, de voorloper van het Koloniaal Instituut. Het legaat van zijn weduwe aan deze instelling hoeft ons dus niet te verbazen.

Het filigrain kan deels op de reis door Indië zijn gekocht. Waarschijnlijker is echter dat de collectie in de loop van vele jaren in Nederland is opgebouwd. Een Nederlandse collectie bestaande uit voorwerpen afkomstig uit Azië en Europa, die ogenschijnlijk de techniek van edelmetaaldraad (filigrain) als enig verbindende factor heeft. Vorm en ornament van de objecten duiden op herkomst uit China, India, Indonesië, en Europa. Maar nauwkeuriger determinering kan de collectie in zijn geheel en vele objecten in het bijzonder interessanter maken.

Het kistje in afbeelding 1 is een typisch voorbeeld voor de collectie Wüstevon Gotsch. Het is een bijouteriekistje, op uitstaande voet, met vier bolpootjes, twee scharnierende deurtjes en daarachter zes laatjes. Op het dakvormig deksel zijn bloemornamenten gesoldeerd. Bovenop het deksele access 
bevindt zich een liggende leeuw met tussen zijn voorpoten een vergulde bol. Aan de zijkanten zijn twee draaibare draaghengsels aangebracht en op de deurtjes is in het draadwerk een staande leeuw verwerkt. De hoeken worden gevormd door gedraaide pilaren. Boven de deurtjes is de vergulde dubbele adelaar van het keizerrijk Oostenrijk-Hongarije bevestigd. Deze adelaar heeft in de ene poot de scepter en het rijkszwaard, en in de andere de rijksappel. Beide koppen dragen de keizerlijke kroon. Onder de poten hangt een banier, die beide poten verbindt. Het gehele wapen is uitgevoerd in verguld zilver. Uitgaande van de toegepaste filigrain-techniek met zeer dunne draden, is het waarschijnlijk dat dit voorwerp in China, of in ieder geval door Chinese handwerkslieden, is gemaakt. ${ }^{9}$ Het zal een bestelling zijn geweest, mogelijk voor de kroning van Franz Josef en Elisabeth tot koning en koningin van Hongarije in juni 1867.

Een interessante anekdote staat vermeld in een folder van restaurant de Uilenboom in Santpoort-Zuid. Het restaurant is gevestigd in 'het chalet' dat onderdeel vormde van landgoed Spaarnberg: 'Barones Olga von Gotsch bood keizerin Sissi of wel Hare Majesteit Elisabeth van Oostenrijk het chalet aan als verblijfplaats om te genezen van haar reuma (...) gedurende de periode van 2 mei 1884 tot en met juni 1884. Officieel heeft keizerin Sissi hier meerder malen met en zonder gevolg gelogeerd.' Verklaart dit de herkomst van het kistje en is het een geschenk van de keizerin van Oostenrijk aan haar vriendin Olga Wüste-von Gotsch?

\section{Filigrain-techniek}

Volgens de algemene definitie zijn filigrain-voorwerpen opgebouwd uit filum (draad) van zilver of goud, en granum (korrel). Een eerste categorie bestaat uit voorwerpen die uitsluitend uit draad zijn opgebouwd. Bij de tweede categorie is plaatwerk toegepast ter ondersteuning. Een voorbeeld hiervan is een bijzondere doos die in 2002 in dit blad werd besproken. ${ }^{10}$ De filigrainobjecten in collectie 229 behoren alle tot de eerste categorie. In zijn standaardwerk Traditional Jewellery of India beschrijft Oppi Untracht de in India toegepaste techniek voor het maken van filigrain-objecten. ${ }^{11}$ In een Indiaas filigrain-object worden drie typen draad gebruikt, elk met een eigen functie. De buitenste draad, die het frame aangeeft en het dikste is, is vierkant in doorsnede; deze 'frame-draad' geeft de contouren van het basisontwerp aan en biedt steun aan alles hierbinnen. De tweede draad is lichter en eveneens vierkant. Deze draad verdeelt de ruimte binnen het buitenste frame in kleinere compartimenten; hij vormt de hoofdlijnen van het ornament, bijvoorbeeld bloemen of bladeren. De derde draad is gemaakt van twee ronde in elkaar gedraaide dunne draden, die vervolgens zijn geplet door te hameren op een aambeeld of met behulp van een pletmolen (afb. 2). Voor het opvullen van het ornament wordt van te voren een voorraad standaardvormen gemaakt.

Abeelding $2 a$ en $b$ (volgende pagina's) Onderzetters, zilverfiligrain, $19 \times 15 \mathrm{~cm}$., Chinees werk, $19^{\circ}$ eeuw, collectie Tropenmuseum, nr. 229-102 a/b.
Chinees filigrain is vrijer van opbouw. Na vaststelling van de vorm wordt deze in zilverdraad uitgelegd. Vervolgens wordt het ornament met zilverdraad of gouddraad ingevuld, met hier en daar, waar nodig, een dikkere draad als steun. Deze dikkere draad is een onderdeel van het gehele ornament (afb. 3). De tentoonstelling in de Amsterdamse Hermitage 'Zilver; het wonder uit het Oosten; filigrain van de tsaren' toonde in 2006 een interessant overzicht van de verschillende zilverdraadtechnieken uit China en India. Maria Menshikova, conservator in de Hermitage in St. Petersburg, beschrijt in de bijbehorende 



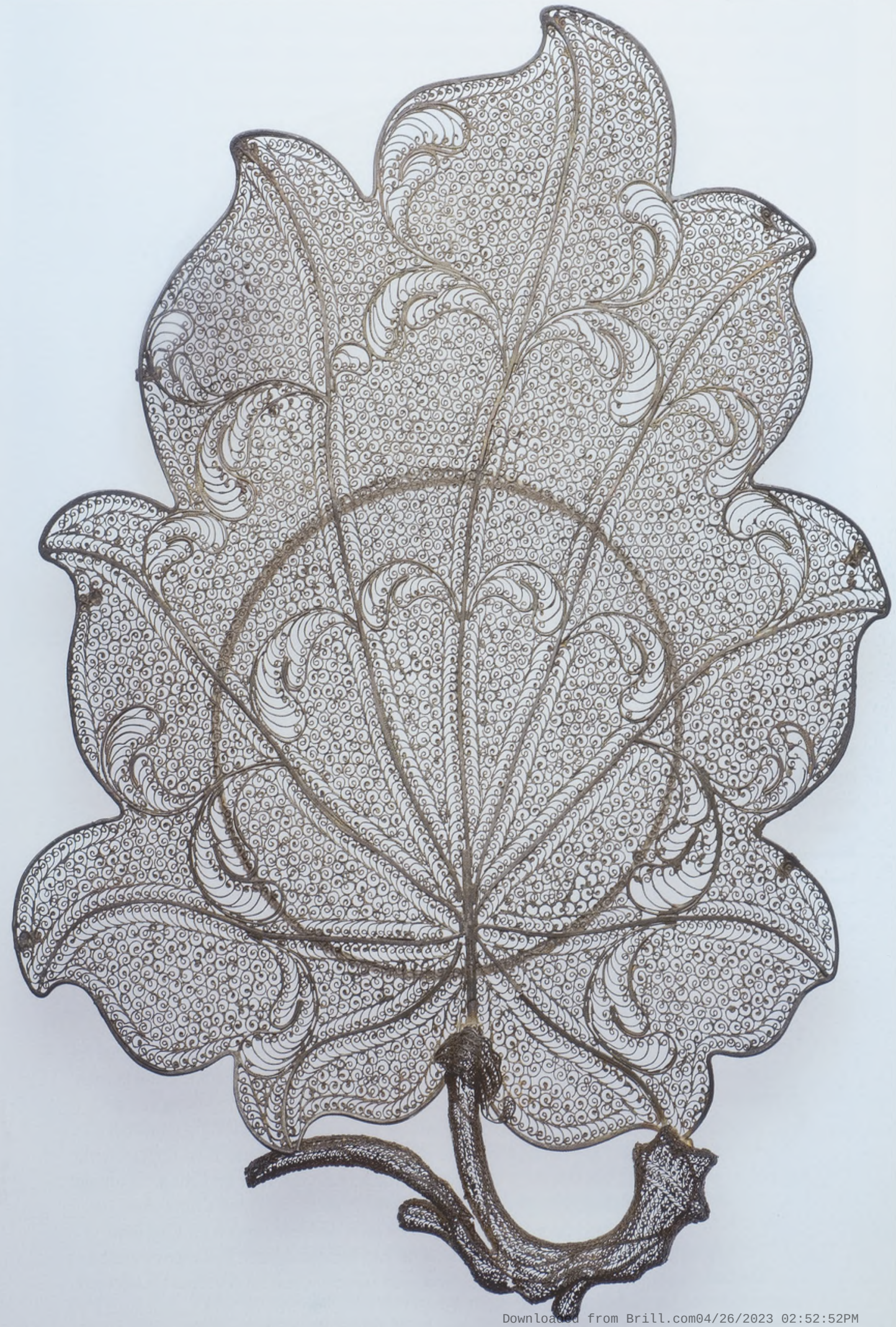

via free access 


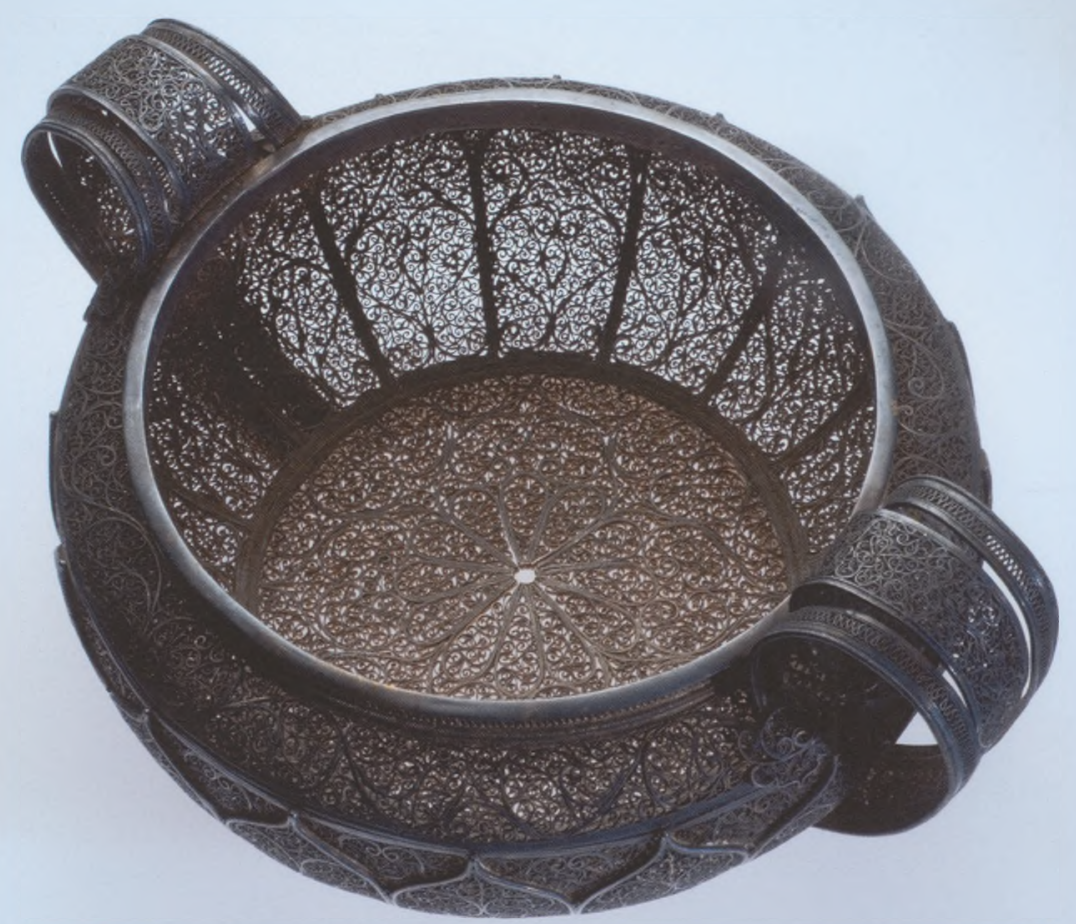

Afbeelding 3

Schaal met oren, zilverfiligrain, diameter $12 \mathrm{~cm}$., hoogte $8 \mathrm{~cm}$., Indiaas werk, Karimnagar?, collectie Tropenmuseum, nr. 229-94. Foto Paul Romijn catalogus de techniek van Chinese edelsmeden. ${ }^{12}$ Het metaal werd daar aanvankelijk tot dunne platen geslagen, in repen geknipt en tot zeer dunne draden getrokken. Kleine korreltjes metaal werden gewoonlijk toegevoegd als decoratie. Een keizerlijke gouden filigrain-kroon is gevonden in een graftombe uit de Wanli-periode (1573-1619). Hieruit valt af te leiden dat de filigraintechniek in ieder geval sinds de $17^{\mathfrak{e}}$ eeuw werd toegepast. De Kantonese ambachtslieden uit de $18^{\mathrm{e}}$ en $19^{\mathrm{c}}$ eeuw werden geroemd om hun vakmanschap en vaardigheid. ${ }^{13}$ In deze periode werd geen gebruik meer gemaakt van de geknipte stroken, maar kenmerkte het Chinese filigrain zich door het vrije gebruik van dunne draden.

\section{Verspreiding over de wereld}

Vanaf de $16^{\mathrm{c}}$ en $17^{\mathrm{e}}$ eeuw werd de filigrain-techniek in bijna alle Europese en Aziatische landen toegepast. Een belangrijke factor voor het tot stand komen van een universele stijl waren de ontdekkingsreizen: de vergroting van de invloedssfeer van de Europese landen mede door de oprichting van OostIndische Compagnieën in Portugal, Spanje, de Nederlanden en Engeland, ter ontwikkeling van de zeehandel met India, Zuidoost-Azië en China. ${ }^{14}$ Portugal was het eerste Europese land dat handelsbetrekkingen met China sloot, in 1511, gevolgd door Spanje in 1565 en later de Nederlanden en Engeland. Het ruilmiddel was zilver in de vorm van Mexicaanse en Spaanse zilveren munten, die door de Chinezen werden omgesmolten en gevormd tot zilveren objecten. ${ }^{15}$ 
Niet alleen de Oostindische compagnieën dreven handel met Azië, ook Spaanse galjoenen die over de Grote Oceaan tussen China, de Filippijnen, Mexico en Spanje voeren (1571-1815), droegen bij aan de verspreiding van kostbare objecten en van technieken, vormen en decoratietechnieken. Manila was de spil van de Spaanse handel, het entrepot waar ook goederen uit Japan en India bijeengebracht werden voor verdere verscheping. ${ }^{16}$ Mede als gevolg van deze levendige handel met Manila als centrum, ontstond in de Filippijnen een groeiende Chinese gemeenschap van ambachtslieden. Chinese edelsmeden vervaardigden voor de export, al dan niet op bestelling, een veelheid van objecten. Villegas vermeldt dat Manila in het begin van de $18^{e}$ eeuw goudfiligrain-objecten via de East-India Company exporteerde naar Madras. ${ }^{17}$ De Portugezen en Spanjaarden waren bekend met zilverfiligrain. Zij gingen het bestellen in Kanton (China) en mogelijk ook in Luzon (Filippijnen), waar eveneens een grote groep Chinese ambachtslieden woonde. ${ }^{18} \mathrm{Zij}$ gaven Europese prototypes mee om na te maken in China. Maar al gauw werden deze voorbeelden ook in India gemaakt, waar de Portugezen via Goa een levendige handel dreven. Zo kunnen we vaststellen dat in vele Indiase werkplaatsen filigrain-voorwerpen werden gemaakt in de Chinese techniek en in de Europese stijl.

Wat determinering van filigrain-objecten in Europese collecties, zoals collectie 229 in het Tropenmuseum, zo moeilijk maakt is dat de handel en onderlinge beïnvloeding minstens een twee-richting verkeer was. ${ }^{19}$

\section{Indiaas en Chinees werk nogmaals vergeleken: twee toiletsets}

Menshikova bestudeerde twee groepen filigrain-zilverwerk, toiletsets van tsarina Catherina de Grote, één uit China en één uit India.

Vanaf de $16^{\mathrm{e}}$ eeuw tot de $18^{\mathrm{e}}$ eeuw ontvingen bruiden van Europese en Russische koningshuizen dikwijls een toiletset als huwelijksgeschenk. Het belangrijkste object van zo'n set was de spiegel; de toiletartikelen werden hieromheen geschaard. In de $17^{e}$ en $18^{e}$ eeuw waren Chinese voorwerpen en chinoiserieën in de mode. Filigrain werd via de Oost-Indische Compagnieën in Azië besteld, omdat de voorwerpen daar goedkoper en fijner afgewerkt waren. ${ }^{20}$

De grootste toiletset in de Hermitage in St.Petersburg is van Chinees zilverfiligrain. Hij was van keizerin Catherina de Grote van Rusland die in 1745 trouwde met prins Ulrich van Holstein Gottorp. De set bestond uit 33 voorwerpen: dozen, sprinklers, schaaltjes en parfumflesjes, met als centraal topstuk een grote staande spiegel. ${ }^{21}$

De Indiase toiletset is in Karimnagar gemaakt halverwege de $18^{\mathrm{e}}$ eeuw. $\mathrm{Hij}$ bestaat uit 19 onderdelen, met de grote staande spiegel als belangrijkste object. Vergeleken met de Chinese toiletset ${ }^{22}$ zijn de onderdelen van de Indiase toiletset strakker van vorm en ornament, in overeenstemming met de beschrijving die Oppi Untracht geeft in zijn 'anatomie van een filigrainobject. ${ }^{23}$ Door de twee toiletsets te vergelijken zien we hoe de filigraindraden, basis van de objecten, verschillend voorbereid zijn. Ook is er verschil te zien in de basisvorm, de opbouw van het object en het ornament.

Vergelijken we tenslotte de voorwerpen in collectie 229 op basis van de hierboven beschreven verschillen in techniek tussen Chinese en Indiase herkomst, dan kunnen we (voorzichtig) vaststellen dat de meeste voorwerpen een Chinese herkomst hebben wat betreft techniek en ornament. Mogelijk access 
komen de meeste hiervan uit Zuid-Sumatra (Palembang) in Indonesië en zijn ze vervaardigd door aldaar wonende Chinezen. ${ }^{24}$ Een tiental voorwerpen zou uit India afkomstig kunnen zijn, eveneens te beoordelen naar de gebruikte techniek.

\section{Conclusie}

Kennis van techniek en ornamentiek is essentieel voor de beschrijving en documentatie van een object en draagt bij tot de vaststelling van de 'provenance' van het voorwerp. Maar ook kennis over de 'provenance' van de collectioneur is essentieel voor de context-beschrijving van object en collectie. Het ontbreken daarvan kan een collectie 'verweesd' doen belanden in het museumdepot waar zij dan tot vergetelheid gedoemd is.

\section{Noten}

1. Brief nr. 516/24 dd 29 september 1924, archief Tropenmuseum Amsterdam.

2. brief 539/24, archief Tropenmuseum Amsterdam.

3. De Hollandse Meesters van een Amsterdamse Bankier; de verzameling van Adriaan van der Hoop 1778-1854 (tent.cat. Amsterdams Historisch Museum), Amsterdam, 2004.

4. De Hollandse Meesters, p. 11

5. De Hollandse Meesters, noot 27, p. 206.

6. De Hollandse Meesters, noot 38. Voor informatie over Spaarnberg, zie ook K. Gnirrep, 'De Schat van Spaarnberg', Amstelodanum (2004).

7. J.G. Fontein was familielid, medebewoonster op Spaanberg, erfgenaam en executeurtestamentair.

8. Krantenknipsels in CBG bij overlijden Wüste.

9. Vooral gekenmerkt door de zeer dunne draden, geknipte repen kwamen in deze periode niet meer voor.

10. J. van Campen, 'Een bijzondere doos van zilver-filigrain', Aziatische Kunst 32/4 (2002), pp. 2-9.

11. O. Untracht, Traditional Jewellery of India, Londen, 1997, pp. 296-299.

12. M. Menshikova, Chinese Export Silver; the Chan collection, Singapore, 2005.

13. Menshikova, Op.cit. (noot 12) p. 14.

14. M. Menshikova, Zilver; het wonder uit het Oosten; filigrain van de tsaren (tent.cat. Hermitage Amsterdam), Zwolle, 2006.

15. Menshikova, Op.cit. (noot 14), p. 20.

16. R.N. Villegas, Kayaman; the Philippine jewelry tradition, Manila, 1983, p. 112.

17. R.N. Villegas, Hiyas; Philippine jewellery heritage, Manila, 1997, p. 81.

18. Villegas, Op.cit. (noot 16), p. 114.

19. Niet alleen uit China en het Indiase subcontinent is veel filigrain-werk bekend, ook uit Zuidoost-Azië, waaronder Indonesië (West- en Zuid-Sumatra, Zuid-Sulawesi, Midden-Java en Bali).

20. Menshikova, Op.cit. (noot 12), p. 15.

21. Menshikova, Op.cit. (noot 14), pp. 51 e.v.

22. Menshikova, Op.cit. (noot 14), afbeelding tegenover p. 59.

23. Untracht, Op.cit. (noot 11), p. 298.

24. Andere filigrain-plaatsen in Indonesië zijn of waren Zuid-Sulawesi (Kendari), Kota Gede bij Yogyakarta in Midden-Java en Celuk in Bali. De techniek in deze plaatsen is dezelfde als de 'Chinese', maar de ornamentiek is zeer verschilend. 